\title{
PENGARUH STRATEGI EVALUASI PEMBELAJARAN PENDIDIKAN AGAMA ISLAM TERHADAP PRESTASI BELAJAR SISWA DI MTSN TAMBAKBERAS JOMBANG.
}

\author{
Oleh: Siti Ajizah \\ Universitas Pesatren Tinggi Darul 'Ulum Jombang
}

\begin{abstract}
Abstrak
Untuk meningkatkan mutu evaluasi pembelajaran PAI sangat diperlukan suatu penilaian yang selama ini diperlukan, yaitu penilaian kognitif, afektif dan psikomotorik. Bagi siswa evaluasi pembelajaran PAI merupakan motivasi untuk meningkatkan prestasi belajar, sehingga guru PAI hendaknya harus peka dan selalu memotivasi siswa meningkatkan prestasi belajar dengan cara melaksanakan strategi evaluasi pembelajaran.

Penelitian ini menggunakan pendekatan kuantitatif untuk mengetahui hubungan antara evaluasi pembelajaran PAI dengan prestasi belajar siswa MTsN Tambakberas Jombang. Populasi penelitian dengan menggunakan 20 responden dari jumlah guru yang mengajar PAI di kelas VII. Metode pengumpulan data dengan angket tertutup dokumentasi dan observasi.

Hasil analisis data dengan menggunakan korelasi Product Moment diperoleh bahawa nilai hasil $r$ hitung lebih besar dari pada $r$ table $(0,757>0,423)$ pada taraf signifikan $95 \%$, hal ini berarti terdapat hubungan yang signifikan antara strategi evaluasi pembelajaran PAi dengan prestasi belajar siswa di MTsN Tambakberas Jombang.

Kata kunci : Strategi, Evaluasi Pembelajaran, Prestasi Siswa dan Korelasi Product Moment.
\end{abstract}

\section{PENDAHULUAN}

\section{Latar Belakang}

Upaya memperbaiki dan meningkatkan mutu pendidikan seakan tidak pernah berhenti. Banyak agenda reformasi yang telah, sedang dan akan dilaksanakan. Beragam pula program inovatif ikut serta memeriahkan reformasi pendidikan. Reformasi pendidikan adalah memperbaiki pola hubungan sekolah dengan lingkungannya dan pemerintah., pola pengembangan perencanaan, pemberdayaan guru dan model-model pembelajaran .

Kurikulum, proses pembelajaran dan penilaian merupakan tiga dimensi yang sangat penting dari sekian banyak dimensi yang ada dalam pendidikan. Ketiga dimensi tersebut saling berkaitan antara satu dengan lainnya. Kurikulum merupakan suatu rencana yang memberi pedoman atau pegangan dalam proses kegiatan belajar mengajar. ${ }^{1}$

Dalam upaya meningkatkan mutu evaluasi pembelajaran pendidikan agama Islam yang meliputi Al-Qur'an Hadist, Fiqih, SKI, Aqidah Akhlaq dan Bahasa Arab MTsN Tambakberas Jombang, maka sangat diperlukan suatu penilaian yang dilakukan bukan hanya terfokus pada satu 
aspek saja (kognitif) seperti yang selama ini dilakukan, tetapi harus menyeluruh, selain aspek kognitif juga aspek efektif dan aspek psikomotorik.

Pendidikan Agama Islam yang merupakan salah satu mata pelajaran di sekolah $\backslash$ madrasah yang penuh dengan muatan nilai kehidupan Islami, perlu diupayakan melalui perencanaan pembelajaran yang baik agar dapat mempengaruhi pilihan, putusan dan pengembangan kehidupan murid. Oleh karena itu salah satu kemampuan yang harus dimiliki oleh guru adalah membuat perencanaan pembelajaran secara profesional dalama melaksanakan tugas dan tanggung jawabnya sebagai seorang pendidik, pembelajar sekaligus sebagai perancang pembelajaran. ${ }^{2}$

Hal ini sesuai dengan UU Sisidiknas pada pendidikan dan tenaga kependidikan pada BAB XI pasal 39 ayat (2) yang berbunyi:

"pendidik merupakan tenaga professional yang bertugas merencanakan dan melaksanakan proses pembelajaran, menilai hasil pembelajaran, melakukan pembimbingan dan pelatihan, serta melakukan penelitian dan pengabdian kepada masyarakat terutama bagi pendidik pada perguruan tinggi."”

Dalam upaya meningkatkan mutu pendidikan, strategi evaluasi pembelajaran PAI senantiasa akan berpengaruh terhadap prestasi siswa. Karena hal ini akan menjadi penunjang didalam pencapaian tingkat prestasi yang lebih tinggi. Strategi evaluasi pembelajaran akan berjalan dengan baik apabila guru dapat mengembangkan kemampuan dasar yang dimiliki. Dengan demikian seorang guru yang memiliki kompentasi yang tinggi dan memenuhi persyaratan-persyaratan yang diperlukan akan dapat melaksanakan tugasnya dengan baik dan tanggung jawab.

Dari uraan diatas, maka peneliti sangat tertarik untuk mengadakan penelitian lebih lanjut tentang, "Hubungan Antara Strategi Evaluasi Pembelajaran Pendidikan Agama Islam Dengan Prestasi Belajar Siswa kelas VII di MTsN Tambakberas Jombang."

\section{Rumusan Masalah}

Berdasarkan latar belakang masalah yamng peneliti kemukakan, maka dapat peneliti kemukakan beberapa permasalahan, yaitu:

1. Bagaimanakah pelaksanaan strategi evaluasi pembelajaran Pendidikan Agama Islam kelas VII di MTsN Tambakberas Jombang?

2. Adakah hubungan Strategi evaluasi pembelajaran Pendidikan Agama Islam dengan prestasi belajar siswa kelas VII di MTsN Tambakberas Jombang? 


\section{Metodologi penelitian}

Didalam penelitian tahap penganalisaan data memegang peran yang sangat penting. Sebab apabila data-data yang telah terkumpul hendaknya dianalisa secara cermat dan lebih teliti sesuai dengan ketentuan-ketentuan yang berlaku pada teknik analisa data. Penggunaan teknik analisa data harus disesuaikan dengan jenis data yang diperoleh dari metode utama. Dengan kata lain statistic merupakan cara terbaik untuk menyusun dan mengelola data-data yang berupa angka-angka.

Untuk dalam penelitian ini analisa data yang digunakan adalah analisis statistic korelasi product moment untuk mengetahui ada tidaknya pengaruh strategi evaluasi pembelajaran PAI terhadap prestasi belajar siswa MTs Negeri Tambakberas Jombang.

Adapun rumus korelasi product moment adalah sebagai berikut:

$$
r_{x y}=\frac{\sum x y}{\sqrt{\left(\sum x^{2}\right)\left(\sum y^{2}\right)}}
$$

keterangan : $\mathbf{r x y}_{\mathrm{x}}=$ Koefisien Korelasi Variabel $\mathrm{x}$ dan variabel $\mathrm{y}$.

$\sum \mathrm{xy}=$ Hasil kali dari $\mathrm{x}$ kali $\mathrm{y}$.

$\sum \mathrm{x}^{2}=$ Jumlah skor yang q1 di kuadrakan dalam nilai skor angket dikurangi nilai rata-rata angket.

$\sum \mathrm{y}^{2}=$ Jumlah skor yang di kuadratkan dalam nilai raport dikurangi nilai ratarata raport.

\section{ANALISIS HASIL PENELITIAN}

\section{Hasil Analisis}

Berdasarkan rekapitulasi jawaban angket dari para guru PAI untuk 20 responden diperoleh nilai Strategi Pembelajaran PAI (variable X) dan nilai hasil Pembelajaran siswa (variable Y) seperti tertera pada table 4.1 sebagai berikut : 
Tabel 1 Nilai Variabel Strategi Evaluasi Pembelajaran PAI dan Nilai Hasil Pembelajaran Siswa MTsN Tambakberas Jombang

\begin{tabular}{|l|l|l|}
\hline $\begin{array}{l}\text { No. } \\
\text { Responden }\end{array}$ & $\mathbf{X}$ & $\mathbf{Y}$ \\
\hline $\mathbf{1}$ & 75 & 76,67 \\
\hline $\mathbf{2}$ & 80 & 77,50 \\
\hline $\mathbf{3}$ & 55 & 71,00 \\
\hline $\mathbf{4}$ & 75 & 75,00 \\
\hline $\mathbf{5}$ & 70 & 76,67 \\
\hline $\mathbf{6}$ & 80 & 75,00 \\
\hline $\mathbf{7}$ & 60 & 68,33 \\
\hline $\mathbf{8}$ & 95 & 80,00 \\
\hline $\mathbf{9}$ & 85 & 71,67 \\
\hline $\mathbf{1 0}$ & 85 & 77,5 \\
\hline $\mathbf{1 1}$ & 70 & 71,67 \\
\hline $\mathbf{1 2}$ & 80 & 75,00 \\
\hline $\mathbf{1 3}$ & 85 & 78,33 \\
\hline $\mathbf{1 4}$ & 70 & 74,00 \\
\hline $\mathbf{1 5}$ & 85 & 75,00 \\
\hline $\mathbf{1 6}$ & 80 & 78,33 \\
\hline $\mathbf{1 7}$ & 85 & 77,33 \\
\hline $\mathbf{1 8}$ & 95 & 81,67 \\
\hline $\mathbf{1 9}$ & 80 & 75,00 \\
\hline $\mathbf{2 0}$ & 90 & 77,50 \\
\hline
\end{tabular}

\section{Kenormalan Data Variabel.}

Data yang baik adalah data yang memiliki distribusi normal, hal terkait dengan validitas data variable baik untuk variable strategi evaluasi maupun variable nilai hasil pembelajaran siswa. Hasil analisis data dengan Porgram SPSS terlihat pada table berikut: ${ }^{18}$.

Table 2. Deskripsi Statistik Normalitas Data

\section{Descriptive Statistics}

\begin{tabular}{|l|r|r|r|r|r|}
\hline & \multicolumn{1}{|c|}{$\mathrm{N}$} & \multicolumn{2}{|c|}{ Skewness } & \multicolumn{2}{c|}{ Kurtosis } \\
\cline { 2 - 6 } & \multicolumn{1}{|c|}{ Statistic } & Statistic & Std. Error & Statistic & Std. Error \\
\hline Strategi Evaluasi PAI & 20 & -.656 & .512 & .476 & .992 \\
Nilai Hasil Pembelajaran & 20 & -.359 & .512 & .340 & .992 \\
Valid N (listwise) & 20 & & & & \\
\hline
\end{tabular}

Kenormalan distribusi data dapat ditunjukkan pada nilai skewness, yaitu nilai kecondongan distribusi data. Semakin mendekati nilai nol, berarti data berdistribusi normal. Pada table 4.2 terlihat bahwa nilai skewness variable strategi evaluasi sebesar 0,656 dan variable 
nilai pembelajaran sebesar 0,359 , yang mendekati nilai nol. Ini berarti data dari kedua variable berdistribusi normal dan memenuhi syarat kevalidan data. Validnya data terlihat dari sifat data yang memiliki distribusi normal.

\section{Deskripsi Variable}

Hasil analisis data dengan menggunakan program computer statistic SPSS Versi 10.0 seperti terlihat pada table berikut:

Tabel 3. Deskripsi Variabel trategi Evaluasi dan Nilai Hasil Pembelajaran Siswa.

Descriptive Statistics

\begin{tabular}{|l|r|r|r|r|r|r|}
\hline & \multicolumn{1}{|c|}{$\mathrm{N}$} & \multicolumn{1}{|c|}{ Minimum } & Maximum & \multicolumn{1}{c|}{ Sum } & \multicolumn{1}{c|}{ Mean } & Std. Deviation \\
\hline Strategi Evaluasi PAl & 20 & 55.00 & 95.00 & 1580.00 & 79.0000 & 10.33645 \\
Nilai Hasil Pembelajaran & 20 & 68.33 & 81.67 & 1510.67 & 75.5335 & 3.18836 \\
Valid N (listwise) & 20 & & & & & \\
\hline
\end{tabular}

Pada table 3 diatas terlihat bahwa strategi evaluasi pembelajaran PAI di MTsN Tambakberas Jombang nilai minimum sebesar 55,00 dan nilai tertinggi sebesar 95,00 dengan nilai rata-rata 79,00. Hal ini berarti bahwa strategi pembelajaran yang dilakukan oleh para guru PAI adalah tinggi dengan demikian sebagian besar guru telah melakukan evaluasi pembelajaran dengan sangat baik.

Nilai hasil pembelajaran diperoleh nilai minimum 68,33 dan nilai maksimum 81,67 dan nilai rata-rata sebesar 75,53. Secara umum nilai hasil pembelajaran di MTsN Tambakberas Jombang adalah baik.

\section{Analisis Korelasi}

Untuk melihat ada tidaknya pengaruh antara variable tingkat kemanjaan siswa dengan nilai kreativitas dilakukan uji statistic dalam bentuk analisis Korelasi Perason Product Momen. Hasil analisis terlihat pada table berikut: 
Tabel 4. Hasil Analisis Korelasi Pearson Product Momen

\section{Correlations}

\begin{tabular}{|ll|r|r|}
\hline & & $\begin{array}{c}\text { Strategi } \\
\text { Evaluasi PAl }\end{array}$ & $\begin{array}{c}\text { Nilai Hasil } \\
\text { Pembelajaran }\end{array}$ \\
\hline Strategi Evaluasi PAl & Pearson Correlation & 1 & $.757^{* *}$ \\
& Sig. (2-tailed) & & .000 \\
& $\mathrm{~N}$ & 20 & 20 \\
\hline Nilai Hasil Pembelajaran & Pearson Correlation & $.757^{* *}$ & 1 \\
& Sig. (2-tailed) & .000 & 20 \\
& $\mathrm{~N}$ & 20 & \\
\hline
\end{tabular}

${ }^{* *}$. Correlation is significant at the 0.01 level (2-tailed).

Pada table 4. di atas terlihat bahwa nilai korelasi antara Strategi Evaluasi Pembelajaran PAI dan Nilai Hasil pembelajaran sebesar 0,757, yang memiliki hubungan korelasi kuat. Hal ini berarti terdapat hubungan yang kuat antara Strategi Evaluasi pembelajaran dengan nilai hasil pembelajaran siswa sehingga strategi evaluasi pembelajaran berpengaruh sangat nyata (signifikan) terhadap prestasi belajar siswa MTsN Tambakberas Jombang.

Berdasarkan arah korelasi diperoleh nilai positif, yang berarti antara strategi evaluasi pembelajaran PAI dan nilai hasil pembelajaran memiliki hubungan yang positif dimana semakin tinggi nilai strategi evaluasi pembelajaran PAI akan menaikkan nilai hasil pembelajaran siswa, begitu pula sebaliknya.

\section{Analisis Korelasi secara Manual}

Hasil analisis korelasi dari dua variable penelitian diperoleh sebagai berikut:

$$
r_{x y}=\frac{\sum x y}{\sqrt{\left(\sum x^{2}\right)\left(\sum y^{2}\right)}}
$$

keterangan : $\mathbf{r}_{x y}=$ Koefisien Korelasi Variabel $\mathrm{x}$ dan variabel $\mathrm{y}$.

$$
\begin{aligned}
& \sum x y=489,02 \\
& \sum x^{2}=2.029,00 \\
& \sum y^{2}=196,92
\end{aligned}
$$

Jadi $r_{x y}=\frac{489,02}{\sqrt{(2.029,00)(196,92)}}=\frac{489,02}{\sqrt{399.550,68}}=0,757$ 


\section{Uji Hipotesis}

Hasil hitung yang diperoleh dari perhitungan di atas adalah sebesar 0,757. Pada table $r$ Product Moment dengan N=20 diperoleh harga table sebesar 0,423 (taraf signifikan 95\%), sedangkan criteria yang berlaku adalah hasil hitung dikonsultasikan dengan $r$ table dengan ketentuan sebagai berikut:

a. Apabila $\mathrm{r}$ hitung $\geq \mathrm{r}$ table pada taraf signifikan (kepercayaan) 95\% dinyatakan sangat signifikan.

b. Apabila $\mathrm{r}$ hitung $\leq \mathrm{r}$ table pada taraf signifikan (kepercayaan) 95\% dinyatakan tidak signifikan. Dengan demikian dapat disimpulkan bahwa hasil $r$ hitung lebih besar dari pada $r$ table $(0,757>$ 0,423 ) pada taraf signifikan $95 \%$, hal ini berarti terdapat hubungan yang signifikan antara strategi evaluasi pembelajaran PAi dengan prestasi belajar siswa di MTsN tambakberas Jombang.

\section{KESIMPULAN DAN SARAN}

\section{Kesimpulan}

a. Hasil angket terhadap strategi evaluasi pembelajaran PAI di MTsN Tambakberas Jombang nilai minimum sebesar 55,00 dan nilai tertinggi sebesar 95,00 dengan nilai ratarata 79,00. Hal ini berarti bahwa strategi pembelajaran yang dilakukan oleh para guru PAI adalah tinggi dengan demikian sebagian besar guru telah melakukan evaluasi pembelajaran dengan sangat baik.

b. Nilai hasil pembelajaran diperoleh nilai minimum 68,33 dan nilai maksimum 81,67 dan nilai rata-rata sebesar 75,53. Secara umum nilai hasil pembelajaran di MTsN Tambakberas Jombang adalah baik.

c. Nilai hasil $r$ hitung lebih besar dari pada $r$ table $(0,757>0,423)$ pada taraf signifikan 95\%, hal ini berarti terdapat hubungan yang signifikan antara strategi evaluasi pembelajaran PAi dengan prestasi belajar siswa di MTsN tambakberas Jombang.

\section{Saran-saran.}

a. Dari hasil penelitian menunjukkan bahwa strategi evaluasi yang dilakukan para guru PAI sudah baik, perlu dipertahankan dan selalu dikembangkan terus agar strategi tersebut terus memberikan peningkatan prestasi belajar siswa.

b. Perlu dilakukan lebih lanjut terkait dengan strategi pembelajaran terhadap tingkat kelulusan siswa terutama hasil ujian nasional. 


\section{DAFTAR PUSTAKA}

Ahmad Ahmadi dan Drs.joko Tri prasetyo, 2005. Strategi Belajar Mengajar, Bandung: Pustaka Setia

Anas Sudijono, 2005.Pengantar Evaluasi Pendidikan, Jakarta: Raja Grafinda Persada.

Arikunto, Suharsisni,. 2002 Prosedur penelitian suatu pendekatan praktek. Jakarta: Rineka Cipta. 2003Dasar-dasar Evaluasi Pendidikan. Jakarta: Bumi Aksara.

Bagong Suyanto dan Sutinah, 2005Metode Penelitian Sosial Berbagai Alternatif Pendekatan. Jakarta: Kencana .

Bhuono Agung Nugroho, SE., M.Si., Akt., 2005 Strategi Jitu Memilih Metode Statistik Penelitian dengan SPSS. Yogyakarta: Penerbit Andy.

Depdikbud, 1989. Kamus Besar Bahasa Indonesia. Jakarta: Balai Pustaka,

Daryanto, 1999. Evaluasi Pendidikan, Jakarta: Rineka Cipta.

Dahlan Al Barry. 1999. Kamus Ilmiah Populer, Surabaya: Arkola.

Hadi amirul dan Haryono, 1998. Metodologi penelitian Pendidikan. Bandung: Pustaka Setia,

Lalu Muhammad Ashar, 1993 Proses Belajar Mengajar, Surabay: Usaha Nasional

Majid, Abdul.2004, Pendidikan Agama Islam Berbasis Kopetensi Remaja Bandung: Rosdakarya.

Ngalim Purwanto. MP. 1992 Prinsip-Prinsip dan Teknik Evaluasi pengajaran. Bandung: PT.Remaja Rosdakarya

Undang-undang Sisdiknas 2003, Tentang sistem pendidikan nasional. media abadi, Jakarta. 